\title{
TEXTOR: A PIONEERING DEVICE FOR NEW CONCEPTS IN PLASMA-WALL INTERACTION, EXHAUST, AND CONFINEMENT
}

\author{
ULRICH SAMM* Institut für Plasmaphysik, Forschungszentrum Jülich GmbH \\ EURATOM Association, Trilateral Euregio Cluster, D-52425 Jülich, Germany
}

Received June 6, 2004

Accepted for Publication August 6, 2004

As an introduction to this special issue, this paper gives a brief overview of the key activities and outstanding results obtained on the TEXTOR tokamak.

KEYWORDS: plasma-wall interaction, wall conditioning, pump limiter

\section{THE TOKAMAK TEXTOR}

The design of the machine aims at optimized experimental conditions for investigations in the field of plasmawall interaction (Tokamak Experiment for Technology Oriented Research). ${ }^{1}$ It provides a circular plasma $(R=$ $1.75 \mathrm{~m}, a=0.46 \mathrm{~m}, B=3 \mathrm{~T}$ ) with excellent access to the boundary for diagnostics. The design provides sufficient flexibility to allow for the implementation and demonstration of new methods, many of them pioneered on TEXTOR as documented in this special issue of Fusion Science and Technology.

TEXTOR is located in Forschungszentrum Jülich, Germany. Operation and scientific exploitation started in 1983. Since 1996 TEXTOR has been operated jointly by a cooperation of three EURATOM associations: the Trilateral Euregio Cluster (TEC) comprising Forschungszentrum Jülich, the Royal Military Academy ERM-KMS (Brussels, Belgium), and the FOM Rijnhuizen Institute of Plasma Physics (Nieuwegein, The Netherlands). The most important cooperation with institutes outside Europe (Japan, United States, and Canada) is organized under the umbrella of an International Energy Agency implementing agreement.

The means for plasma heating beyond ohmic heating $(\mathrm{OH})$, which is typically in the range of 300 to $400 \mathrm{~kW}$,

*E-mail: u.samm@fz-juelich.de has been extended over the years: first in 1984 by radiofrequency in the ion cyclotron range (4 MW) (Ref. 2) and then in 1988 by neutral beam injection (4 MW). Later, in 2001 electron cyclotron resonance heating also was added $(1 \mathrm{MW})$ in order to provide a well-localized heat source for profile control. ${ }^{3}$ In total, $\sim 9 \mathrm{MW}$ of heating is now available, corresponding to a maximum heating density of $1 \mathrm{MW} / \mathrm{m}^{3}$ or an average radial heat flux density at the plasma boundary of $0.25 \mathrm{MW} / \mathrm{m}^{2}$.

\section{MAIN ACHIEVEMENTS}

With the installation of the pump limiter Advanced Limiter Test ${ }^{4}$ (ALT-II) in 1987, which is a full toroidal belt limiter equipped with turbopumps, efficient $\mathrm{He}$ exhaust has been demonstrated for the first time in a tokamak. ${ }^{5}$ These studies also led to the derivation of an important figure of merit for $\mathrm{He}$ exhaust: The ratio $\tau_{\mathrm{He}}^{*} / \tau_{E}$ of the effective helium exhaust time and the energy confinement must stay below a certain maximum value to allow for a steady-state burning fusion plasma. ${ }^{6}$ The maximum value depends on the presence and amount of other impurities in the plasma. The ALT-II limiter also opened the possibility for a better density control as well as the control of impurity species, like noble gases, which played a significant role in the development of the concept of plasma edge cooling with seeded impurities.

TEXTOR turned from a machine with metallic walls and limiters into a "low-Z machine" starting in 1985 by changing the limiter material from steel to graphite and, most important, by introducing low- $\mathrm{Z}$ wall coatings. This pioneering method of wall coatings is based on a glow discharge in reactive gases providing a thin amorphous hydrogen-containing layer from different materials depending on the type of gases used, e.g., carbonization, boronization, or siliconization. ${ }^{7}$ With such conditioning methods significant improvements of the operational range (e.g., density limit, stability) of TEXTOR and other tokamaks have been achieved. ${ }^{8}$ For the development of these 
methods, the powerful baking capabilities in TEXTOR for vessel and liner played an important role.

Rather clean plasmas with only low-Z impurities and the possibility for feedback control of noble gases with the help of the pump limiter ALT-II have been the essential elements in the development of a plasma scenario with a radiative plasma mantle. It has been first demonstrated on a high power level on TEXTOR that radiation cooling (90\% of total power) with seeded noble gases (neon, argon) is possible by employing feedback control of the radiation level. ${ }^{9}$

In such plasmas with a high radiation level, surprisingly, an improved confinement regime at high density with stationary plasma energy and strong edge radiation by seeded and intrinsic impurities has been discovered. This regime has been named radiative improved mode (RI-mode). ${ }^{10}$ The mode combines many features simultaneously: power load on large areas via radiation, operation at high densities (above the Greenwald density), good energy confinement, and quasi stationarity (160 energy confinement times, limited only by the flux swing of the transformer). For the latter aspect, it was essential that in 1994 the magnetic flux swing of TEXTOR was doubled to $8.8 \mathrm{~V} \cdot \mathrm{s}$ by upgrading the $\mathrm{OH}$ system. With this improvement the pulse length for standard operation at $350 \mathrm{kA}$ increased from 3 to $\sim 10 \mathrm{~s}$.

The investigation of radiation-cooled plasmas on TEXTOR as well as later on other devices led to a deeper insight into transport mechanisms. It has been demonstrated that the suppression of ion temperature gradient instabilities is one of the main causes for density peaking and confinement improvement in the RI-mode. ${ }^{11}$ The corresponding modeling could also explain that a confinement improvement can be achieved on smaller machines (TEXTOR) with much less impurity seeding $\left(Z_{\text {eff }}\right)$ than in larger devices [Joint European Torus ${ }^{12}$ (JET)]. Knowledge about mechanisms that led to limitations of the operational range (density limit, radiative instabilities, beta limit and tearing modes, strong gas fueling) of radiation-cooled plasmas has been gained.

The flexibility of the TEXTOR facilities that give access to the plasma periphery paved the way for many investigations. Among these, a system of air locks allows the insertion on a day-to-day basis of different test limiters or other devices with a diameter of $\sim 10 \mathrm{~cm}$. These devices can be moved in a radial direction, rotated, externally heated, combined with gas puffing, or be electrically biased. ${ }^{13}$ An important application of such an air lock was the introduction of a movable electrode in order to investigate the effect of externally imposed radial electrical fields to the plasma edge and in general to study the role of the electric field for bifurcation phenomena observed during confinement improvements, like the L-mode-to-H-mode transition. ${ }^{14}$

The investigation of plasma-wall interaction has been an outstanding issue on TEXTOR (Ref. 15). This comprises the mostly nonlinear link between edge processes and plasma core properties, as is, e.g., evident in the RI-mode or the effect of wall conditioning, as well as the investigation of detailed processes and mechanisms on the surface of wall components. The basis of these investigations is among other features the excellent access via the air locks and the possibility to apply comprehensive diagnostics through the many flanges available. The development of particular diagnostics optimized for the plasma boundary is a main focus on TEXTOR (Ref. 16). Pioneering work in edge diagnostics has been achieved in the fields of atomic beam-assisted spectroscopy, ${ }^{17}$ highresolution emission spectroscopy, laser-induced fluorescence, and colorimetry.

After the changeover of TEXTOR to low-Z walls, it became evident from spectroscopic measurements that under these circumstances chemical processes are significant for the erosion of wall components. ${ }^{18}$ Also, there was evidence for hot spot formation on carbon limiters due to thermal electron emission. Simulation of erosion and deposition of carbon with the ERO Monte Carlo code $^{19}$ and detailed comparison of data from TEXTOR and JET gave evidence for a long-range transport due to an enhanced reerosion rate of deposited carbon. ${ }^{20}$

The comprehensive and detailed edge plasma diagnostics combined with the possibility to control surface properties of wall elements (surface material, surface temperature, angle of inclination, etc.) within the air locks led to significant new insight into the recycling processes of hydrogen atoms and molecules and its isotopomers. Different velocity components from reflected atoms, dissociation products, and charge-exchange processes depending on the surface conditions and excitation state of the molecules have been identified. ${ }^{21}$ In particular, these processes are of importance for the modeling of the highdensity low-temperature divertor of ITER, as is done in the EIRENE Monte Carlo code for neutral particle transport, which has been developed in Jülich and is used in most fusion laboratories worldwide, often in connection with two- or three-dimensional plasma transport codes. ${ }^{22}$

The latest novel installation on TEXTOR for pioneering a new concept is the dynamic ergodic divertor (DED), a development following the first ergodic divertor experiments on Tore Supra (Ref. 23), which was implemented in TEXTOR in 2001-2002 and started operation in the middle of 2003 (Ref. 24). This new concept aims at the control of energy and particle exhaust based on the ergodization of the magnetic field in the plasma boundary by perturbation coils on the high-field side and by a near field (laminar zone), which will divert the plasma onto the graphite divertor plates. The DED has the option of rotating the perturbing field poloidally with frequencies up to $10 \mathrm{kHz}$. This opens a new area of research aiming at the investigation of external coils as a means for the control of plasma transport and instabilities.

Development, exploration, and refinement of new diagnostics for plasma boundary and core to be used at TEXTOR as well as preparatory work for other devices 
(JET, ITER, and Wendelstein 7-X) belong to one of the main activities on TEXTOR. The first remarkable result on TEXTOR in this respect was the accurate measurement of the central current density by polarimetry showing that the central safety factor $q$ stays below one during the whole sawtooth cycle, which was in contrast to the theories at that time. ${ }^{25} \mathrm{X}$-ray spectroscopy also has been improved with impact on the use of these methods in astronomy. ${ }^{26}$ Other methods and diagnostics are still under development with TEXTOR as a test bed. ${ }^{27}$

\section{REFERENCES}

1. O. NEUBAUER et al., "Design Features of the Tokamak TEXTOR,” Fusion Sci. Technol., 47, 76 (2005).

2. R. $\mathrm{KOCH}$ et al., "Ion Cyclotron Resonance Heating on TEXTOR,” Fusion Sci. Technol., 47, 97 (2005).

3. E. WESTERHOF et al., "Electron Cyclotron Resonance Heating on TEXTOR," Fusion Sci. Technol., 47, 108 (2005).

4. K. H. FINKEN et al., "The Toroidal Pump Limiter ALT-II in TEXTOR,” Fusion Sci. Technol., 47, 126 (2005).

5. D. HILLIS et al., Phys. Rev. Lett., 65, 2382 (1990).

6. D. REITER, G. H. WOLF, and H. KEVER, Nucl. Fusion, 30, 2141 (1990).

7. V. PHILIPPS, "Wall Conditioning on TEXTOR," Fusion Sci. Technol., 47, 119 (2005).

8. J. WINTER et al., J. Nucl. Mater., 162-164, 713 (1989).

9. U. SAMM et al., Plasma Phys. Control. Fusion, 35, B167 (1993).

10. R. R. WEYNANTS et al., Nucl. Fusion, 39, 1637 (1999).

11. M. TOKAR et al., Phys. Rev. Lett., 84, 895 (2000).

12. B. UNTERBERG et al., "The Radiative Improved Mode at TEXTOR: Power Exhaust and Improved Confinement at High Density," Fusion Sci. Technol., 47, 187 (2005).
13. B. SCHWEER et al., "Limiter Lock Systems at TEXTOR: Flexible Tools for Plasma-Wall Investigation," Fusion Sci. Technol., 47, 138 (2005).

14. R. R. WEYNANTS et al., "Electrode Biasing on TEXTOR: A Tool for Fundamental Physics Studies," Fusion Sci. Technol., 47, 202 (2005).

15. U. SAMM et al., Plasma Phys. Control. Fusion, 41, B57 (1999).

16. S. BREZINSEK et al., "Plasma Edge Diagnostics for TEXTOR," Fusion Sci. Technol., 47, 209 (2005).

17. E. HINTZ and B. SCHWEER, Plasma Phys. Control. Fusion, 37, A87 (1995).

18. A. POSPIESZCZYK et al., J. Nucl. Mater., 989 266-269, 138 (1999).

19. A. KIRSCHNER et al., Nucl. Fusion, 40, 989 (2000).

20. A. KIRSCHNER et al., "Overview of Erosion Mechanisms, Impurity Transport, and Deposition in TEXTOR and Related Modeling," Fusion Sci. Technol., 47, 146 (2005).

21. PH. MERTENS et al., Plasma Phys. Control. Fusion, 43, 349 (2001).

22. D. REITER et al., "The EIRENE and B2-EIRENE Codes," $F u$ sion Sci. Technol., 47, 172 (2005).

23. P. GHENDRIH, A. GROSMAN, and H. CAPES, Plasma Phys. Control. Fusion, 38, 1653 (1996).

24. K. H. FINKEN (Guest Editor), Special Issue: Dynamic Ergodic Divertor (15 articles of different authors), Fusion Eng. Des., 37, 335 (1997).

25. H. SOLTWISCH, W. STODIEK, J. MANICKAM, and J. SCHLÜTER, Proc. 11th Int. Conf. Plasma Phys. and Control. Nucl. Fusion Res., Vienna, Austria, p. 263, International Atomic Energy Agency (1987).

26. G. BERTSCHINGER, Phys. Scr., T83, 132 (1999).

27. A. J. H. DONNÉ et al., "Overview of Core Diagnostics for TEXTOR,” Fusion Sci. Technol., 47, 220 (2005). 